\title{
On Innovative and Entrepreneurial Talent Cultivation Strategies in China Local Colleges
}

\author{
Dong-yan $\mathrm{Li}^{1,}$, , Qing-feng Guo 2,b \\ ${ }^{1}$ College of Humanities and Social Sciences, Hei Longjiang Bayi Agricultural University, Daqing, Hei \\ Longjiang, China, 163319; \\ ${ }^{2}$ College of Information Technology and Sciences, Hei Longjiang Bayi Agricultural University, \\ Daqing, Hei Longjiang, China, 163319; \\ aredsun_2002@163.com, bgqfafg@126.com
}

Keywords: innovative and entrepreneurial education, research-oriented teaching, practice teaching, talents in local colleges

Abstract. China has in recent years launched a series of policies and measures to promote the reform of college innovation and entrepreneurship education in light of college quality standards, revising the curriculum system, teaching evaluation and so on, rendering the goal of innovative and entrepreneurial orientation more focused. Nowadays, local colleges are actively putting creative teaching idea of education into practice, striving to become the leader of innovative thinking and practice. This thesis explores the innovative and entrepreneurial talent training strategies at the micro-level from the perspectives of the creative education idea, the research-oriented teaching and practice teaching in local colleges aiming to provide beneficial reference to innovative and entrepreneurial cultivation of talents in local colleges.

\section{Introduction}

In the traditional education of our country are contained course, curriculum and examination as the assumed social need of knowledge and ability like Chinese, mathematics and foreign language. Every child accepts the knowledge of traditional education and becomes a master of professional knowledge talent after ten years of school; however, some students are lack of professional talents; some students are not interested in their professional fields; that produces a large number of talents of the same kind, brings about education homogeneity and the lack of uniqueness.

In traditional society, it is not too big a problem, because traditional work needs to learn the same knowledge, master the basic knowledge, That is to say, learners need not accept education voluntarily, but step by step accept the traditional education, preparing for jobs rather than business; to a large extent, the vast majority of people are in passive state to meet the needs of employers. In fact, from this perspective, traditional education adapts to the development of the traditional society and needs; now we are in the era of knowledge economy and the essential requirements is innovation.

THAT requires that we shift knowledge-inheritance centered education thought, establish the education idea of cultivating innovation spirit, and that the main melody of our era is encourage innovation and entrepreneurship.

\section{The cultivation of the idea of innovative and entrepreneurial education}

The idea of innovative and entrepreneurial education may have a long way to go because too many problems left by history as stated earlier need to overcome. More luckily, Chinese government is aggressively breaking through the institutional system to start the reform of higher education all over the country.

\section{The breakthrough of institutional system}

Our President Xi jinping, pointed out when it comes to innovation and entrepreneurship, young students who are rich in imagination and creativity is a creative life force. 
At the national level, the full implementation of entrepreneurship education reform is ongoing; the Chinese government launched a series of innovation and entrepreneurship education reform policies and measures in colleges and universities. The ways of eight funds are supplied from financial input from the government, school project to social risk investment, bank credit, and others via the new policy our country provides. Various colleges and universities from many aspects actively implement the reform requirements, offering a series of guarantee to young students for innovation and entrepreneurship. Campus activities also provide opportunities for students of entrepreneurial projects. Among them, an important guide is especially paying attention to the social resources like enterprises playing in the role of creative talents training. University entrepreneurial talent can be combined with the enterprise culture innovation, which can launch its own practical teaching and business supervisor from the project to the fund to talent configuration, having their own entrepreneurial teams and teaching support team and applying for their attention-paid project, leading students to entrepreneurship.

According to the national bureau of statistics data, it is shown that $2.9 \%$ of the students choose their own business among the undergraduates and poly graduates in 2014; since the new policy, the number is growing exponentially [1]. All that suggests the new adaptable institutional system is being built, which is the indispensable premises for further constant innovation and entrepreneurship.

\section{The cultivation of innovative and entrepreneurial ideas}

Our innovative behavior is decided by our innovative ideas and our innovative ideas is determined by the way we think, so the innovation thinking way is for us of great importance, which is self-evident. It is better to be aware of what values or ideology innovative and entrepreneurial talents have [2].

The first thing is to know that the standard of success or failure innovative undertaking doesn't count solely on earning money; entrepreneurs are exposed to innovative entrepreneurship education, which is this kind of culture with a pioneering spirit, innovative and entrepreneurial staying power. The next is to understand the fact that talents are diversified. As ecological diversity is the necessity of developing ecological health, so is the necessity of diversifying talents. Every person is born to naturally have its own strengths and weaknesses; that is his own uniqueness. As the famous Gardner's multiple intelligences theory claims [3]: one person differs a lot from another in some aspects such as language talent ability, music, art, interpersonal communication, physical condition, mathematics and logic; everyone's pursuit or curiosity and will to pursue power is different; there is motivation. Potential plus efforts makes innovative and entrepreneurial talent. A person will become a master in some thing if 10000 hours are spent in what he is interested in; if he makes up for what he is not interested in, he will become normal.

Therefore, the two aspects, namely, best potential and hard work are utilized for the cultivation of innovative and entrepreneurial ideas. Moreover, it is best to instill in the cultivation of innovative business ideas; family, school and society together work to foster creative thinking which is particularly important and the effect is better. For colleges, undertaking to innovate in the cultivation of entrepreneurial ideas undoubtedly starts from the research-based education.

\section{The focus on research-oriented education}

As above mentioned, the research-oriented education is the route educators had better pass which unfolds as the following points go one after another.

\section{The encouragement of personalized development}

The principle of research-oriented education advocates: teachers are guides; students are the center; teacher-student relation is equal; the interaction between teachers and students, promotes common development; teaching is learning. In other words, the classroom is the stage of the communication between teachers and students, the dialogue and exploration of learning in which the teachers and students participate.

Class is where teachers guide and inspire students independently explore knowledge, let them freely and independently discuss and debate. Students can, if necessary, negate what teachers say, rather than 
follow the teacher. That is encouraging the personalized development of learners in education, as is also considered the respect, trust, love of the teaching objects, revealing higher interpersonal expectation. According to the previously mentioned theory of multiple intelligences, the examination can only examine students' language, mathematical and logic intelligence, for other intelligence is rarely involved. Therefore, the single test scores measuring a student is very one-sided; based on any evaluation from different angles, everyone can be the first. Because it allows students autonomous organizations and participation in the activities of education and learning according to their own interests and hobbies which is a kind of fun and passionate learning, stimulating the brain to the greatest extent and giving full play to people's sensory function such as hearing, vision and touch.

This requires university teachers to launch the reform of teaching contents and teaching methods in education.

\section{The extension of classroom teaching}

What is taught in class should contain not only the full contents of books but something outside books also and closely related with the in-class theme that includes teachers' research results and scientific research experience, history and reality of living examples, the formation process of knowledge and the story of the famous people, etc.; the proportion of inside-class and outside-class contents is about $75 \%$ to $25 \%$. During teaching process, teachers must inspire and guide students to ask questions and allow students proper thinking time and space to analyze problems, making clear what the nature of the problem is, what the method to solve the problem is, knowing the use of quantitative and qualitative approach and encouraging discussion and conclusions. Here it should be pointed out that, teachers must be responsible for their own part whereas students should have their own research within the scope of their ability to grasp things. Classroom is a communication platform for intellectual activity between teachers and students, where teachers impart the teaching ideas and activate students' thinking, walking in a classroom watching students' listening state while students had better respond to the teacher's questions, there being a dialogue between teachers and students.

\section{The reform of teaching method}

The reform of teaching methods should start first in changing teaching ideas and respect the subject status of students in learning activities at the same time; the best teachers in the different stages of the elaborate design teaching process inspire students' thinking and in the process of communication and discussion is a good guide. As teachers, guiding students into thinking is a kind of important responsibilities. Some students don't think and seldom love asking questions to whom the teacher must not yield and sometimes even "force" thinking upon them and kindly urge them to answer the questions. More important, in-class learning teachers ought to pay more attention to the application of the research-oriented teaching method and extracurricular study is focused on research on the basis of fundamental training, guiding students to study some questions they can; experimental teaching emphasizes independent design, even if the stipulated one, students aren't told what to do. The purpose of doing so is to cultivate students' creative ability.

Generally speaking, the preliminary creative characteristics of creation ability are embodied in the inquisition ability, the imaginative ability associated with the new things, the ability of collecting information and the initial creative personality characteristics such as strong self-confidence, questioning, intense curiosity, and strong will. In traditional teaching, related studies have shown that students' creative thinking is the main obstacle: too stringent, mindset, conformity, the information saturation, a trend that grows with the growth of the age. Therefore, the cultivation of the innovative and entrepreneurial talents must start from the reform of teaching method, overcoming the cramming teaching, endowing students with live and active learning. In parallel to this is the reform of exam system and grading standards, completely changing the teaching system and test assessment which are based on the rote learning; practice the diversification of assessment mode and evaluation standard with the test being plural, which is good for cultivating innovative talents.

In short, what is taught is focused on academic depth through the inspiration, the guide during interactive teaching process whereas extracurricular learning focuses on research and experiment teaching on independent design with tests stimulating thinking and encouraging innovation. Teaching 
methods and teaching experience are for inheritance, accumulation and innovation and what teachers do is making the greatest efforts to form the individualized teaching style.

\section{The attachment of great importance to innovative and entrepreneurial practice training}

The power of knowledge lies in action. Practical ability requests us to regard knowledge as the ability of action. Famous educator Tao xingzhi's "action is the beginning of knowledge; learning is to ask" profoundly reveals the truth. College education often gives priority to theoretical teaching rather than practice training based on the facts. What needs to be done is transfer from the past teaching knowledge to the exploration of research-based teaching, fusing power for innovative and entrepreneurial practice training.

The execution of creative teaching practice training involves three methods. The first thing is to make students become no pure knowledge explorer and can be directly involved in scientific research activities which undergraduates only graduate students in the past can take part in. The second is to equip each of undergraduate students a mentor and introduce one-on-one instruction in graduate education; the third is to carry out the study with lots of discussion in which undergraduate university offer a large number of courses with discussion and teachers inspire students' enthusiasm, gradually helping them to form scientific exploration spirit. In addition, college students' innovative undertaking usually has some basic aspects as for the quality requirements, such as the ability to solve the problem, independent learning enthusiasm and ability, interpersonal ability, sense of responsibility for the individual and collective action, cultural diversity and a variety of language skills and professional ability etc..

So are just as important the factors: closely collaborative innovation between colleges and enterprises as well as the encouragement of putting into practice theories [4].

\section{Conclusion}

The reform of the traditional teaching way is based on the blend of the practice training with the development of individualized characteristics and the extension of classroom teaching; by means of the cooperation of brains and hands, the new system may be well established with the combination of practical teaching and professional study, innovative undertaking and employment entrepreneurship. The mission of colleges is to further strengthen inseparable relationship between college students and the related industries to make college students' innovative undertaking live up to the required basic skills and qualities.

\section{References}

[1] Information on http://politics.people.com.cn/n/2015/0513/c1001-26993805. html.

[2] Yao Yanping. Innovation education calls for education [J]. Journal of education research, vol. 3 (2000), p.32-36.

[3] Howard Gardner. Shen Zhilong (translator). The structure of the intelligence [M]. Beijing: China renmin university press (2008).

[4] Gu shengzu. The exploration of reforming teaching practice in traditional mode [J]. Journal of education research, vol. 8 (2003), p55 - 60.

\section{Author Introduction}

The first author: Dong-yan li, 1978, female, lecturer; major study field: foreign language teaching and multimodal discourse, e-mail: redsun_2002@163.com. 
Corresponding author: Qing-feng guo, 1976, male, lecturer; major field: computer science and technology, e-mail: gqfdfg@126.com. 